Acknowledgments: KS was supported by the "Excellence Initiative - Research University" programme as a member of the team "Bioinformatics in medical \& population genomics".

Disclosure of Interests: Katarzyna Skonieczna Grant/research support from: KS was supported by the "Excellence Initiative - Research University" programme as a member of the team "Bioinformatics in medical \& population genomics", Dominika Mlicka: None declared, Anna Woźniacka: None declared, Rafał Czajkowski: None declared, Ewa Robak: None declared, Mariusz Gawrych: None declared, Anna Duleba: None declared, Tomasz Grzybowski: None declared

DOI: 10.1136/annrheumdis-2020-eular.4195

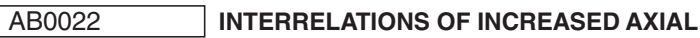 SPONDYLOARTHRITIS ACTIVITY AND THE SERUM CONCENTRATION OF IMMUNOGLOBULIN A TO CD74 WITH GENETIC POLYMORPHISMS OF INTERLEUKIN 17 ALLELES}

E. Vasilenko $^{1,2}$, M. Korolev ${ }^{3}$, S. Lapin ${ }^{4}$, I. Kholopova ${ }^{4}$, A. Dadalova ${ }^{1}$, V. Mazurov ${ }^{1}$, I. Gaydukova ${ }^{1,2} .{ }^{1}$ North-Western State Medical University named after I.I. Mechnikov, Department of Therapy, Rheumatology, Examination of Temporary Disability and Quality of Medical Care named after E.E. Eichwald, St. Petersburg, Russian Federation; ${ }^{2}$ St. Petersburg Clinical Rheumatology Hospital No.25, St. Petersburg, Russian Federation; ${ }^{3}$ The Federal Research Center Institute of Cytology and Genetics, Novosibirsk, Russian Federation; ${ }^{4}$ The First Pavlov State Medical University of St. Petersburg, Laboratory for Diagnostics of Autoimmune Diseases, St. Petersburg, Russian Federation

Background: Genetic predisposition takes one of the main parts at pathogenesis of axial spondyloarthritis (axSpA). Currently, HLA-B27 is a single genetic marker that used in classification criteria of axSpA. However, the presence of HLA-B27 does not affect the activity of the disease. An alternative biomarker of axSpA activity could be an immunoglobulin (Ig) A antibody to an invariant chain peptide associated with class II human leukocyte antigen (HLA) (anti-CD74).

Objectives: The goal is to determine genetic polymorphisms of IL17 alleles prevalence in patients (pts) with axSpA and their interrelations with the disease activity and concentration of IgA to CD74.

Methods: In 48 patients with a reliable diagnosis of axSpA, aged 18 to 69 years ASDAS, BASDAI, BASFI were calculated. The polymorphisms of alleles of interleukin (IL)-17A197 a/g, IL-17F7 histidine (His)/arginine (Arg), IL-17F11139 c/g, HLA-B27 were evaluated. Serum concentration of IgA to CD74 was measured (the normal reference interval according to the instructions for the laboratory kit for serum IgA to CD74 is $0-12.0 \mathrm{U} / \mathrm{L}$ ).

Results: The mean age of pts was $45.1 \pm 14.2$ years, male $72.9 \%$, BASDA $2.99 \pm 0.28$, ASDAS $2.29 \pm 0.16$ (Cronbach's alpha for the scales -0.830 ), $\lg A$ to CD74 $16.9 \pm 11.0 \mathrm{mg} / \mathrm{L}$. The most often found polymorphisms of interleukin-17 alleles demonstrated in table 1.

Table 1. Interleukin-17 alleles' polymorphisms in patients with axia spondyloarthritis, $n=48$

\begin{tabular}{lccc}
\hline Indicator & $\begin{array}{c}\text { Pts with presence of } \\
\text { polymorphism, } n\end{array}$ & Indicator & $\begin{array}{c}\text { Pts with presence } \\
\text { of polymorphism, } n\end{array}$ \\
\hline IL-17A-197 AA & 14 & IL-17F7 his/his & 45 \\
IL-17A-197 GG & 18 & IL-17F7 his/arg & 2 \\
IL-17A-197 GG & 16 & IL-17F7 arg/arg & 1 \\
IL-17F-11139 CG & 26 & IL-17F-11139 CC & 22 \\
\hline
\end{tabular}

Exceeded levels of IgA to CD74 were identified at 96 pts $(70.1 \%)$. The factor analysis showed a relationship between ASDAS $(R=0.857)$, BASDAI $(R=0.842)$, BASFI ( $R=0.857$ ) and level of IgA to CD74 ( $R=0.667)$, (table 2).

Table 2. Interrelations between serum concentration of IgA to CD74, the activity indices and genetic polymorphisms of interleukin-17 alleles in axSpA patients (factor loads), $n=48$

\begin{tabular}{lccr}
\hline Indicator & \multicolumn{3}{c}{ Factor loading (R) } \\
\hline Factor & Factor 1 & Factor & Factor 1 \\
\hline IgA anti-CD74 & 0.525 & 0.925 & 0.667 \\
BASDAl & 0.734 & 0.816 & 0.842 \\
ASDAS & 0.657 & 0.576 & 0.857 \\
BASFI & 0.545 & & 0.820 \\
IL-17 F7 His/His & -0.421 & & \\
IL-17F7 His/Arg & 0.631 & 0.544 & \\
\hline
\end{tabular}

An increase in the factor load indices for IgA to CD74 $(R=0.925)$ was established, provided that the IL-17F genotype is homozygous for the his / arg allele $(\mathrm{R}=0.544)$. The genotypes IL-17F his/his showed an inverse interrelation with the increase in serum IgA to CD74 level $(R=-0.421)$.

Conclusion: Serum concentration of IgA to CD74 exceeded normal reference level in axSpA patients in $70.1 \%$ of cases that was associated with ASDAS and BASDAI levels. Presence of heterozygote IL-17F polymorphism in his/arg allele was associated with increasing serum concentration of IgA to CD74 and with increased disease activity (ASDAS and BASDAI). Decreasing of serum IgA to CD74 concentration, less axSpA activity (ASDAS and BASDAI) were found in patients with presence of heterozygote IL-17F polymorphism in his/ his allele.

Disclosure of Interests: Elizaveta Vasilenko: None declared, Maxim Korolev: None declared, Sergey Lapin: None declared, Irina Kholopova: None declared, Anna Dadalova: None declared, V Mazurov: None declared, Inna Gaydukova Grant/research support from: JSC BIOCAD, Speakers bureau: Pfizer, Novartis AbbVie, JSC BIOCAD, Celgene, MSD, Sanofi DOI: 10.1136/annrheumdis-2020-eular.4998

\section{AB0023 ASSOCIATION OF NCF2, NCF4 AND CYBA GENES POLYMORPHISMS WITH RHEUMATOID ARTHRITIS IN A CHINESE POPULATION}

T. P. Zhang ${ }^{1}$, Q. Huang ${ }^{2}$, H. F. Pan ${ }^{2}$, D. Q. Ye ${ }^{2}, \mathrm{X}_{\mathrm{Li}}{ }^{3}$ on behalf of no. ${ }^{1}$ The First Affiliated Hospital of University of Science and Technology of China, Hefei, China; ${ }^{2}$ Anhui Medical University, Hefei, China; ${ }^{3}$ The First Affiliated Hospital of University of Science and Technology of China, Hefei, China

Background: Recent studies have focused on the special roles of NADPH-oxidase, which is composed of gp91phox, p22phox, p47phox, p67phox, p40phox encoded by CYBB, CYBA, NCF1, NCF2, NCF4 genes, in multiple autoimmune diseases. Nevertheless, the association of genetic variation in NADPH-oxidase genes with rheumatoid arthritis (RA) was not extensively studied in Chinese population.

Objectives: We performed this study to examine the association of NCF2, NCF4, CYBA genes polymorphisms with RA susceptibility in a Chinese population Methods: Six single nucleotide polymorphisms (SNPS) (NCF2 rs10911363, NCF4 rs1883112, rs4821544, rs729749, CYBA rs3794624, rs4673) were genotyped in a cohort composed of 593 RA patients and 596 normal controls. All patients were consecutively enrolled from the Department of Rheumatology at the First Affiliated Hospital of University of Science and Technology of China and the First Affiliated Hospital of Anhui Medical University, and the normal controls was enrolled from the same region. Improved multiple ligase detection reaction (iMLDR) was used for genotyping. Chi-square $\left(x^{2}\right)$ test was used to analyze the association of the genotype and allele frequencies of above SNPs and RA. Odds ratios $(O R)$ and $95 \%$ confidence interval $(C /)$ were also evaluated using Logistic regression analyses, and haplotype analysis was assessed using SHEsis software.

Results: There were 101 males and 492 females in RA group with a mean age of $51.59 \pm 6.68$ years, and the normal control group included 97 males and 499 females with an average age of $52.32 \pm 12.63$ years. We observed that NCF4 rs4821544 CT genotype, $\mathrm{C}$ allele frequencies in RA patients were significantly decreased when compared to controls (CT vs. TT: $P=0.043 ; \mathrm{C}$ vs. T: $P=0.031$ ), and rs4821544 polymorphism was significantly associated with an increased RA risk under the dominant model (TT vs. CT+CC: $P=0.031$ ). Moreover, our results also indicated that rs729749 CT genotype frequency was significantly lower in RA patients than that in controls (CT vs. CC: $P=0.033$ ). No significant association between NCF2, CYBA genes polymorphisms and RA susceptibility was observed. There were no significant differences in allele, genotype frequencies of above SNPs between RA patients with RF-positive and with RF-negative, as well as anti-CCP-positive RA patients and anti-CCP-negative RA patients.

Conclusion: In summary, NCF4 rs4821544, rs729749 polymorphisms might contribute to RA susceptibility, while NCF2, CYBA genes polymorphisms were not associated with RA susceptibility.

References:

[1] Nauseef WM. Assembly of the phagocyte NADPH oxidase, Histochem Cell Biol, 2004;122:277-291.

[2] Groemping Y, Rittinger K. Activation and assembly of the NADPH oxidase: a structural perspective, Biochem J (2005) 386:401-416.

[3] Olsson LM, Nerstedt A, Lindqvist AK, Johansson SC, Medstrand P, Olofsson P, et al. Copy Number Variation of the Gene NCF1 Is Associated with Rheumatoid Arthritis, Antioxid Redox Signal(2012)16:71-78.DOI:10.1089/ ars.2011.4013 
Table 1. Genotype and allele frequencies of NCF2, NCF4, CYBA genes polymorphisms in RA patients and controls [n(\%)]

\begin{tabular}{|c|c|c|c|c|c|}
\hline SNP & Analyze model & & $\mathrm{RA}(\mathrm{N}=593)$ & Control $(\mathrm{N}=596)$ & $P$ value \\
\hline \multicolumn{6}{|l|}{ NCF2 } \\
\hline \multirow[t]{5}{*}{ rs10911363 } & Genetypes & GG & 125 & 144 & 0.371 \\
\hline & & GT & 304 & 289 & 0.747 \\
\hline & & TT & 164 & 163 & \\
\hline & Alleles & G & 554 & 577 & 0.408 \\
\hline & & $\mathrm{T}$ & 632 & 615 & \\
\hline \multicolumn{6}{|l|}{ NCF4 } \\
\hline \multirow[t]{5}{*}{ rs1883112 } & Genetypes & GG & 57 & 56 & 0.972 \\
\hline & & GA & 248 & 255 & 0.754 \\
\hline & & AA & 288 & 285 & \\
\hline & Alleles & G & 362 & 367 & 0.888 \\
\hline & & A & 824 & 825 & \\
\hline \multirow[t]{7}{*}{ rs4821544 } & Genetypes & $\mathrm{CC}$ & 4 & 7 & 0.323 \\
\hline & & CT & 117 & 146 & 0.043 \\
\hline & & TT & 472 & 443 & \\
\hline & Alleles & C & 125 & 160 & 0.031 \\
\hline & & $\mathrm{T}$ & 1061 & 1032 & \\
\hline & Dominant model & TT & 472 & 443 & 0.031 \\
\hline & & $\mathrm{CT}+\mathrm{CC}$ & 121 & 153 & \\
\hline \multirow[t]{5}{*}{ rs729749 } & Genetypes & TT & 104 & 102 & 0.445 \\
\hline & & CT & 266 & 302 & 0.033 \\
\hline & & CC & 223 & 192 & \\
\hline & Alleles & $\mathrm{T}$ & 474 & 506 & 0.219 \\
\hline & & C & 712 & 686 & \\
\hline \multicolumn{6}{|l|}{ CYBA } \\
\hline \multirow[t]{5}{*}{ rs3794624 } & Genetypes & AA & 14 & 15 & 0.929 \\
\hline & & GA & 160 & 147 & 0.368 \\
\hline & & GG & 419 & 43 & \\
\hline & Alleles & A & 188 & 177 & 0.498 \\
\hline & & $\mathrm{G}$ & 998 & 1015 & \\
\hline \multirow[t]{5}{*}{ rs4673 } & Genetypes & AA & 1 & 5 & 0.140 \\
\hline & & GA & 85 & 90 & 0.673 \\
\hline & & $\mathrm{GG}$ & 507 & 501 & \\
\hline & Alleles & A & 87 & 100 & 0.34 \\
\hline & & G & 1099 & 1092 & \\
\hline
\end{tabular}

Acknowledgments: no

Disclosure of Interests: None declared

DOI: 10.1136/annrheumdis-2020-eular.4278

\section{AB0024 ASSOCIATION OF IL6 RS1800795 BUT NOT IL6R RS2228145, RS4845618 AND STAT4 RS7574865 POLYMORPHISMS WITH CHLAMYDIA-ASSOCIATED RHEUMATOID ARTHRITIS}

T. Zybalova ${ }^{1}$, V. Yagur $^{1}$, R. Goncharova ${ }^{2}$, N. Soroka ${ }^{1}$, N. Dostanko ${ }^{1}$, V. Apanasovich ${ }^{1}$, A. Tushina ${ }^{1} .{ }^{1}$ Belarusian State Medical University, 2-nd Department of Internal Medicine, Minsk, Belarus; ${ }^{2}$ Institute of Genetics \& Cytology NAS Belarus, Laboratory of Molecular Basis of Genomic Stability, Minsk, Belarus

Background: Rheumatoid arthritis (RA), associated with Chlamydial Infection, has some clinical and immunological particulars that interfere with the early diagnosis and require significant changes in treatment strategy [1].

Objectives: To estimate the distribution of some non-HLA genetic markers such as STAT4 rs7574865, IL6 rs1800795, IL6R rs2228145 and rs4845618 in Chlamydia positive and negative RA patients and healthy controls.

Methods: We examined 380 healthy blood donors and 187 RA patients classified according to the ACR/EULAR 2010 criteria for RA [2]. Twenty-three of the RA patients were positive for Chlamidia trachomatis $(n=17)$ or Chlamidia pneumonia $(n=6)$ persistence. DNA from peripheral blood samples was extracted by phenol-chloroform method. SNPs were genotyped by the real-time PCR with fluorescent probes. Statistical significance of SNPs' frequency was estimated by two-way Fisher exact test $\left(F, p_{2-t}\right)$ with Bonferroni correction for multiple comparisons $\left(\mathrm{p}_{\mathrm{cor}}\right)$. Moreover, diagnostic odds ratio (dOR), the likelihood ratio of positive $\left(\mathrm{LR}^{+}\right)$and negative $\left(\mathrm{LR}^{-}\right)$tests and corresponding confidence intervals $(\mathrm{Cl})$ were calculated.

Results: We revealed statistically significant increase of genotype CC frequency (IL6 rs 1800795) in Chlamydia-associated RA (60.9\%) vs healthy donors $(20.7 \%)$ : $p_{2-t}=0.000065 ; p_{\text {cor }}=0.00026 ;$ dOR=5.95 $\left(\mathrm{Cl}_{95 \%}\right.$ 2.53-13.94); LR ${ }^{+}=2.94\left(\mathrm{Cl}_{95 \%}\right.$ 1.90-3.29); $\mathrm{LR}^{-}=0.49\left(\mathrm{Cl}_{95 \%}\right.$ 0.28-0.75) as well as in Chlamydia-associated $\mathrm{RA}$ $(60.9 \%)$ vs Chlamydia-negative RA (23.9\%): $p_{2-t}=0.00051 ; p_{\text {cor }}=0.002 ; \mathrm{dOR}=4.99$ $\left(\mathrm{Cl}_{95 \%}\right.$ 2.04-12.16); $\mathrm{LR}^{+}=2.56\left(\mathrm{Cl}_{95 \%} 1.60-3.57\right) ; \mathrm{LR}^{-}=0.51\left(\mathrm{Cl}_{95 \%} 0.29-0.78\right)$. Significant differences in STAT4 rs7574865, IL6R rs2228145 and IL6R rs4845618 distribution between studied groups were not found.

Conclusion: Our data suggest the association between CC genotype of IL6 rs1800795 and Chlamydia-associated RA.

References:

[1] Soroka N.F. Rheumatoid Arthritis, associated with Chlamydial infection // Healthcare 2009; $1: 5-9$
[2] Aletaha D. et al. 2010 Rheumatoid arthritis classification criteria// Arthritis Rheum 2010; 62 (9): 2569-81.

Disclosure of Interests: Tatiana Zybalova: None declared, Viktor Yagur: None declared, Roza Goncharova: None declared, Nikolaj Soroka Grant/research support from: JSC BIOCAD, Natalia Dostanko: None declared, Valery Apanasovich: None declared, Anastasiya Tushina: None declared DOI: 10.1136/annrheumdis-2020-eular.5739

\section{Adaptive immunity ( $T$ cells and B cells) in rheu- matic diseases}

\begin{tabular}{l|l}
\hline AB0025 & B-CELL SUBSETS AS ADDITIONAL DIAGNOSTIC \\
TOOL FOR PRIMARY SJOGREN'S SYNDROME AND \\
SYSTEMIC LUPUS ERYTHEMATOSUS
\end{tabular}

S. Benevolenskaya ${ }^{1}$, I. Kudryavtsev ${ }^{2}$, M. Serebriakova ${ }^{3}$, I. Grigor'eva ${ }^{4}$, A. Budkova ${ }^{5}$, D. Zammoeva ${ }^{4}$, D. Motorin ${ }^{1}$, A. Zaritskey ${ }^{4}$, S. Lapin ${ }^{5}$, A. Maslyanskiy ${ }^{4}{ }^{1}$ Almazov National Medical Research Centre, SaintPetersburg, Russian Federation: ${ }^{2}$ Institute of Experimental Medicine, Saint-Petersburg, Russian Federation; ${ }^{3}$ Institute of Experimental Medicine, Saint-Petersburg, Russian Federation; ${ }^{4}$ Almazov National Medical Research Centre, Saint-Petersburg, Russian Federation; ${ }^{5}$ Pavlov First Saint Petersburg State Medical University, Saint-Petersburg, Russian Federation

Background: Systemic lupus erythematosus (SLE) and primary Sjögren's syndrome (pSS) are chronic complex disorders with an autoimmune background, multifactorial etiology, multiple circulating antinuclear antibodies and damage of various organs. SLE and pSS have several similar clinical and serological aspects; likewise, SLE and Sjögren's syndrome may coexist (so-called secondary Sjögren's syndrome). However, applied classification criteria do not differentiate SLE and pSS. It is known that humoral immunity plays significant part in pathogenesis of those diseases; hereby, we can expect imbalances in B cell subset frequencies during SLE and pSS.

Objectives: To investigate clinical utility of B cell subsets in distinguish SLE and pSS during diagnosis.

Methods: A total of 25 SLE patients, 25 SS patients and 49 healthy volunteers (HV) were included in the study. The diagnosis of SLE was performed according to the 2019 EULAR - ACR classification criteria, the diagnosis of pSS - according to the 2016 EULAR - ACR criteria. Phenotyping of blood B cell subsets was done using flow cytometry. Total peripheral blood $B$ cells were identified using $C D 19$ expression, distinct $B$ cell subsets were characterized by $\operatorname{lgD}, C D 38$ and CD27 expression. All of the statistical analysis of data was performed with STATISTICA Version 12.0 Inc. (USA). Results: We evaluated the percentages of circulating B-cell subsets using three major classification schemes based on the relative co-expression of either IgD/ CD38 (so-called "Bm1-Bm5" classification), IgD/CD27 and CD38/CD27. A discriminant analysis was performed for all B cell classifications. Analysis of CD38 and CD27 co-expression demonstrated most significant separation between patients with SLE and pSS (fig. 1). Moreover, discriminant analysis carried out by using a forward stepwise model demonstrated that the top significance was documented while assessing the percentage of plasmoblasts (CD27hiCD38hi), resting memory B-cells (CD27dimCD38low), mature active B-cells (CD27dimCD38dim), naive mature B-cells (CD27dimCD38low), as well as counting the absolute numbers of transitional B-cells (CD27lowCD38hi), model percent correct was 78,6\% ( $p<0,05$, tab.1).

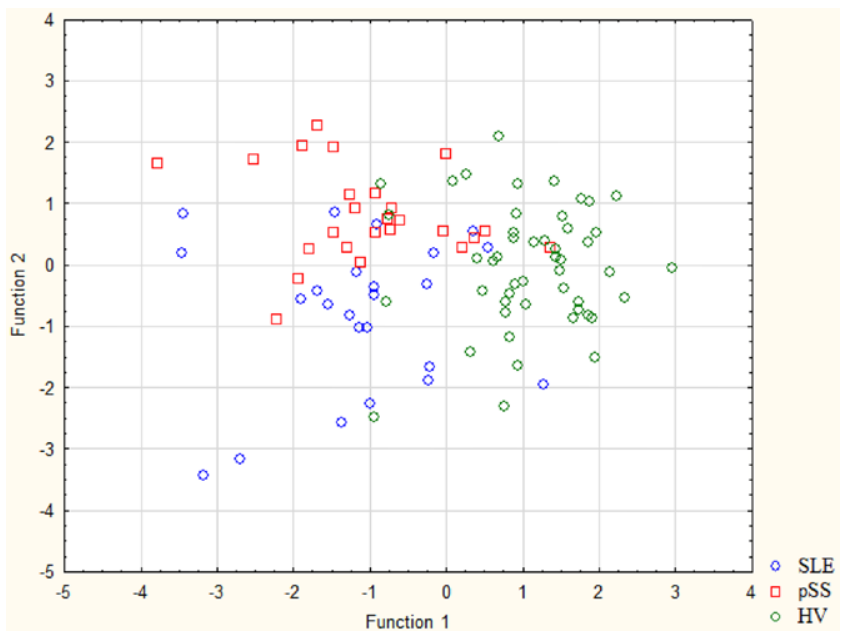

Figure 1. Graphic distribution of SLE and pSS patients as well as HV analyzed by discriminant analysis. 